\title{
Promoting an academic culture in the Arab world
}

\section{ACADEMIC AND ETHICAL ISSUES IN THE ARAB WORLD}

Scientists with high educational level are expected to have a proportionally high ethical standard. However, this is not always the case. A wide chasm between academic levels and ethical conducts and between practical ethics and theoretical knowledge is perceptible in many scientific and medical fields. ${ }^{[1-6]}$ As scholars, we, however, have more responsibility to be ethically and professionally honest in producing knowledge, in interpreting it, in communicating it, and in interacting with each other. Yet, research and science ethics are sometimes superficial and/or broken intentionally or unintentionally at the highest scholarly levels. In the Arab world, which is the main focus of this article, unethical symptoms range from the absence of basic communication ethics (i.e., nonresponse to formal requests or E-mails) to a more serious misconduct in research and medical practice, passing through biased funding and recruitment policies. Such policies are commonly a matter of persistent practices called "wasta" or "wasata" (literally means "intercession") which still cause damages in many Arab countries. ${ }^{[7-9]}$ The wasta is using one's influence or that of others - sometimes with bribery - to gain favors or advantages that otherwise would not be attained easily or at all in for example admissions to universities, gaining employment, getting privileged hospital services, or gaining exclusive business licenses for export or import valued products or goods without any other competitors or providers. It is in fact a universal human phenomenon that has also been reported in other countries, referred as to "guanxi" in China, "jeitinho" in Brazil, or "pulling strings" in Anglo-Saxons countries. ${ }^{[10]}$

The current ethical guidelines in some Arab countries suffer from many ethical shortages relating to the lack of objectivity, flexibility, well-defined research strategies, and overwhelming bureaucracy. ${ }^{[1-13]}$ A lack of outreach activities and an atmosphere of oppressive pressure, selfishness, unethical competition, animosity, and endeavors toward artificial prestige more than toward socioeconomic development ${ }^{[14]}$ is also perceptible in many stances. The absence of research ethics code and misconduct policy leads many scholars to stealing ideas, dishonesty, and plagiarism. ${ }^{[15,16]}$ Such symptoms are also frequently reported from countries that have the most stringent codes and regulations in place because many trainers and trainees, students and teachers alike, are never taught, or do not always understand, the increasing complexity and nuances of what constitutes intellectual thefts, plagiarism, and scientific misconduct. Ethical regulations in many Arab institutions are deficient in many aspects, particularly in relation to development, structure, content, and reference to international ethical guidelines. ${ }^{[17]}$

Despite obvious defects of citation practices, ${ }^{[18]}$ some Arab institutions spend a lot of money to lure "highly cited authors" or to coaffiliate their published papers with institutions abroad to appear with more "prestige" or "excellence" in biased ranking systems such as the Shanghai ranking ${ }^{[19,20]}$ or alike. It is, however, not a question of citations but the utility of manuscripts in real life to bring concrete solutions to health, technical, or environmental challenges. Nonetheless, this issue (the focus on prestige and citation) is not specific to the Arab world but a global issue that needs more attention. The "market of prestige" and misleading "excellence" is a main focus of many Arab and non-Arab scientists and policymakers at all costs sometimes at the expense of deontology and ethics. The scientific enterprise, however, is supposed to be quintessential and disinterested of any superficial or subjective values, such as excellence and prestige which do not make much sense in science.

In spite of some positive and encouraging changes in the Arab academic world (e.g., building new universities, relative increases in research and higher education funds, increases in student numbers and research activities), research in this region is still lagging far behind countries with similar or even less human and natural resources. Research and public health investments in many Arab countries are still limited and rigidly institutionalized with heavy and long procedures and often granted in function of administrative or personal influences only (i.e., resort to wasta as mentioned above). Except oil-exporting countries, Arab expenditures on research and development (R and $\mathrm{D}$ ) have not experienced substantial or worthwhile rapid growth. Egypt, the largest Arab country, spends merely $0.86 \%$ of its gross national product on $\mathrm{R}$ and D compared with $2 \%$ in South Korea and $1.78 \%$ in Taiwan. ${ }^{[21]}$ According to United Nations data of 2014, the gross domestic expenditures on R and D for Egypt, Tunisia, and Bahrain were, respectively, about 0.67, 0.64, and 0.099\% of the gross domestic product (GDP) (http:data.un.org/Data. 
aspx?d=UNESCO\&f=series\%3AST_SCGERDGDP). In all cases, there is no one single Arab country among the 22 countries of the Arab League, including oil-rich countries, that has ever reached the threshold of $1 \%$ of GDP. In 2007, the Arab world spent merely $0.2 \%$ of its GDP on R and D. ${ }^{[22]}$

In terms of scientific publications, which is not necessarily an accurate or an objective indicator of scientific advancement or progress, twenty Arab countries contribute about $0.55 \%$ to the world science literature compared with $0.68 \%$ by Poland and $1.84 \%$ by the Netherlands. ${ }^{[21]}$ Arab countries produce less than $0.5 \%$ of papers published in top-tier medical journals. ${ }^{[22]}$

Research private investments, on another hand, are almost absent in the Arab world, and if any, they are derisory and attributed on personal relationships, as well. The Arab world, however, abounds with important potential public and private financial resources, but they are typically granted to small or immediate consumption profit-generating projects, mostly on a superficial criteria basis, too.

While keeping the sizes of laboratories ${ }^{[23]}$ and universities ${ }^{[24]}$ relatively small and manageable enables better mentoring and better training of scientists, the objectives of many science and research policies in Arab institutions are directed toward bigness of buildings, centralism of roles, and diluted responsibilities. The Arab world is also experiencing a multidimensional change in the higher education system, along with abroad privatization and internationalization of many of its higher education institutions. The Arab Gulf States for example are the largest hosts of international branch campuses worldwide. ${ }^{[25]}$ The United Arab Emirates and Qatar both are hosting up to 50 branches of foreign universities, ${ }^{[26]}$ some of them are struggling. ${ }^{[27]}$ Although such a proliferation could be considered as a win-win strategy for the host and hosted, it could also be seen as a neocolonialism form ${ }^{[31]}$ or a soft power system ${ }^{[28]}$ with many problems. ${ }^{[27]}$ As most of the hosted universities are private with high enrollment fees, affordable only by rich people, economic crises may lead to their failure. ${ }^{[27,29]}$ In fact, importing knowledge passively rather than producing it actively looks like a baroque arsenal promising much but delivering little. ${ }^{[30]}$ Consumers of knowledge that is created, generated, and delivered from elsewhere would remain at the periphery as the imported knowledge and policies, like products, become outdated and old fashioned when new products are available and a long time spans its production and consumption. ${ }^{[30]}$ As helpful as it might be, importing educational policies may be seen as good developmental programs, but, once in situ, they do not necessarily fit well because they may not resonate with local interests. ${ }^{[30]}$ Therefore, the focus on local research priorities is of great importance to solve local issues. Then, when these get fixed at the best way possible, interests in other priorities could be undertaken.

Although great efforts have been made on literacy in the Arab world, some 65 million adults are still illiterate, ${ }^{[31]}$ emphasizing the need for special focus on all learning levels including among the elderly. The role of universities in conducting research and providing lifelong learning and training for youth and adults should thus be an integral part and a continual endeavor of the national strategies for literacy. ${ }^{[31]}$

\section{ROOT CAUSES OF ETHICAL ISSUES IN THE ARAB WORLD}

The failure of current research strategies in many Arab countries is a complex multifactorial issue relating to social, economic, inefficient science and research policy, administrative, and managerial factors. Conflictual culture determinants or structural and organizational factors could also be culprit such as the absence of well-structured educational system, inequality, inadequate funding strategies, materialism, downplayed integrity and honesty, deficiency and lack of proper training and leadership approaches. Other fracturing contradictions between materialistic and unmaterialistic values sometimes lead many people to breach ethical rules and behave in a Machiavellian way to reach their objectives. Reasons may also include corruption, mismanagement, cronyism, nepotism, ${ }^{[32]}$ and waste and misuse of public resources. The reasons behind such misconduct might be due to internal, external, societal, or contextual factors ${ }^{[33,34]}$

\section{POTENTIAL REMEDIES TO OVERCOME THE CHALLENGES}

To remedy the issues mentioned above and to promote academic and ethical cultures in the Arab world, it is important to avoid the root causes mentioned above and to minimize their effects toward more transparency and integrity in science and education policies. To take part in worthwhile scientific achievements and to reduce ethical hazards in Arab countries, Arab scholars and policymakers need to deeply rethink the way research and development policies are currently planned, conveyed, and performed. A particular attention should be paid on local and socioeconomic priorities with the highest ethical and human values considered while avoiding superficiality and misleading metrics in science, such as the deceiving notions of citations, prestige and excellence (Moustafa, 2016). ${ }^{[35]}$ There is a lot of manuscripts cited thousands of 
times but their real or concrete impacts in real life are low or naught, and vice versa.

Although some ethical guidelines already exist in some Arab countries, ${ }^{[17]}$ it would be necessary to create ethical guidelines to cover all the scientific disciplines and situations to emphasize respect of research subjects, fairness, integrity, quest for truth, impartiality, honesty, and modesty.

As prevention is always better than cure, it would be more advantageous to provide the necessary ethical training to all the academic levels, ${ }^{[36]}$ including graduate, undergraduate, and postgraduate levels. Other measures may include the implementation of a formal ethical system to address misconduct acts that should be tailored to local conditions, the simplification of grant applications, the instauration of equal employment and appointments systems that could help bypassing the aforementioned wasta's detrimental effects. Above all, there is no doubt that eradicating corruption at all levels is indispensable. This will depend on a fair and just system of selecting managers and leadership by placing the right person at the right place without any other consideration. The Arabic academic system should also be flexible and adaptable to post-oil era challenges. As the sun and seawater are abundant in the Arab world, such resources should receive more attention in research programs and policies to fit with renewable energy and environmental sustainability goals. For example, breeding new land sea hybrid plant species irrigable with seawater ${ }^{[37]}$ or floating photovoltaic-based agriculture systems in the sea ${ }^{[38]}$ or in greening the desert with seawater and sunlight ${ }^{[39]}$ are few examples among many others that could be undertaken. Health equity should also be a major priority for the present and future of the Arab world. ${ }^{[40]}$ Finally, promoting and enhancing the Arabic language at schools and universities, as a native and first medium for acquiring and tackling modern sciences, is another workshop to leverage the educational level and reduce the gap between Arab societies and their educated elite without, however, neglecting foreign languages learning.

\section{Financial support and sponsorship}

Nil.

\section{Conflicts of interest}

There are no conflicts of interest.

Khaled Moustafa Chief Editor of the Arabic Science Archive (arabixiv.org). E-mail: khaled.moustafa@arabixiv.org

\section{REFERENCES}

1. El-Dessouky HF, Abdel-Aziz AM, Ibrahim C, Moni M, Abul Fadl R, Silverman $\mathrm{H}$, et al. Knowledge, awareness, and attitudes about research ethics among dental faculty in the Middle East: A Pilot study. Int J Dent 2011;2011:694759.

2. Delany CM, Edwards I, Jensen GM, Skinner E. Closing the gap between ethics knowledge and practice through active engagement: An applied model of physical therapy ethics. Phys Ther 2010;90:1068-78.

3. Van Nuland S, Poisson M. Teacher Codes: Learning from Experience. Paris: UNESCO, International Institute for Educational Planning; 2009.

4. Nolen AL, Putten JV. Action research in education: Addressing gaps in ethical principles and practices. Educ Res 2007;36:401-7.

5. Longenecker JG, McKinney JA, Moore CW. The generation gap in business ethics. Bus Horiz 1989;32:9-14.

6. George RJ. Teaching business ethics: Is there a gap between rhetoric and reality? J Bus Ethics 1987;6:513-8.

7. Barnett A, Yandle B, Naufal G. Regulation, trust, and cronyism in Middle Eastern societies: The simple economics of "wasta”. J Soc Econ 2013;44:41-6.

8. Mohamed AA, Mohamad MS. The effect of wasta on perceived competence and morality in Egypt. Cross Cult Manage Int J 2011;18:412-25.

9. Mohamed AA, Hamdy H. The Stigma of Wasta: The Effect of Wasta on Perceived Competence and Morality; 2008.

10. Smith PB, Huang HJ, Harb C, and Torres C. How distinctive are indigenous ways of achieving influence? A comparative study of guanxi, wasta, jeitinho, and "pulling strings". J CrossCult Psychol 2012;43:135-50.

11. Makhoul J, El-Alti L, Qutteina Y, Nasrallah C, Sakr C, Nakkash R, et al. "Protecting" or "Policing": Academic researchers' view of IRBs in an Arab context. J Empir Res Hum Res Ethics 2014;9:25-35.

12. Farazmand A. Bureaucracy and the Alternatives in the Middle East. In: Henderson KM, Dwivedi OP, editors. Bureaucracy and the Alternatives in World Perspective. London: Palgrave Macmillan UK; 1999. p. 244-68.

13. Farazmand A. (1999) Bureaucracy and the Alternatives in the Middle East. In: Henderson K.M., Dwivedi O.P. (eds) Bureaucracy and the Alternatives in World Perspective. International Political Economy Series. Palgrave Macmillan, London.

14. El Obeidy A. Scientific system in the Arab region: From prestige towards development. Reg Sci Policy Pract 2013;5:97-112.

15. Muthanna A. Plagiarism: A shared responsibility of all, current situation and future actions in Yemen. Account Res 2016;23:280-7.

16. Bensalem I, Rosso P, Chikhi S. A new corpus for the evaluation of arabic intrinsic plagiarism detection. In: International Conference of the Cross-Language Evaluation Forum for European Languages. Springer, Berlin, Heidelberg; 2013.

17. Alahmad G, Al-Jumah M, Dierickx K. Review of national research ethics regulations and guidelines in Middle Eastern Arab countries. BMC Med Ethics 2012;13:34.

18. Moustafa K. Aberration of the citation. Account Res 2016;23:230-44.

19. Billaut JC, Bouyssou D, Vincke P. Should you believe in the Shanghai ranking? Scientometrics 2010;84:237-63.

20. Florian R. Irreproducibility of the results of the Shanghai academic ranking of world universities. Scientometrics 2007;72:25-32.

21. Anwar MA, Bakar AA. Current state of science and technology in the Muslim world. Scientometrics 1997;40:23-44.

22. Maziak W. Boosting biomedical research in the Arab world. Avicenna J Med 2011;1:2-3.

23. Stroth $\mathrm{N}$. The central importance of laboratories for reducing waste in biomedical research. Sci Eng Ethics 2016;22:1707-16.

24. Schubert T, Yang G. Institutional change and the optimal size of 
universities. Scientometrics, 2016;108:pp 1129-1153.

25. Wilkins $\mathrm{S}$. Who benefits from foreign universities in the Arab Gulf states? Aust Univ Rev 2011;53:73-83.

26. Becker R. International branch campuses: New trends and directions. Int High Educ 2015;58:3-5.

27. Romani V. The politics of higher education in the Middle East: Problems and prospects. Middle East Brief 2009;36:1-8.

28. Gao S. China's Soft Power in the Arab World through Higher Educational Exchange. Honors Thesis Collection; 2015. Available from: https:// repository.wellesley.edu/thesiscollection/290. [Last accessed 2018 Mar 25].

29. Lewin T. University branches in Dubai are struggling. N Y Times 2009.

30. Donn G, Al Manthri Y. Education in the Broader Middle East: Borrowing a Baroque Arsenal. Oxford, United Kingdom: Symposium Books Ltd.; 2013.

31. Yousif AA. The State and Development of Adult Learning and Education in the Arab State. Hamburg, Germany: UNESCO Institute for Lifelong Learning, Feldbrunnenstraße; 2009.

32. Sidani YM, Thornberry J. Nepotism in the Arab world: An institutional theory perspective. Bus Ethics Q 2013;23:69-96.

33. McCabe DL, Feghali T, Abdallah H. Academic dishonesty in the Middle
East: Individual and contextual factors. Res High Educ 2008;49:451-67.

34. McCabe DL, Trevino LK, Butterfield KD. Cheating in academic institutions: A decade of research. Ethics Behav 2001;11:219-32.

35. Moustafa, Khaled. Publishing, Objectivity, and Prestige. Journal of microbiology and biology education 2016;17:331.

36. Spier RE, Bird SJ. Scientific misconduct: Ongoing developments. Sci Eng Ethics 2000;6:3-4.

37. Moustafa K. Toward breeding new land-sea plant hybrid species irrigable with seawater for dry regions. Plant Signal Behav 2015;10:e992744.

38. Moustafa K. Toward future photovoltaic-based agriculture in sea. Trends Biotechnol 2016;34:257-9.

39. Moustafa K. Greening drylands with seawater easily and naturally. Trends Biotechnol 2017;35:189-91.

40. Rashad $\mathrm{H}$. Health equity in the Arab world: The future we want. Lancet 2014;383:286-7.

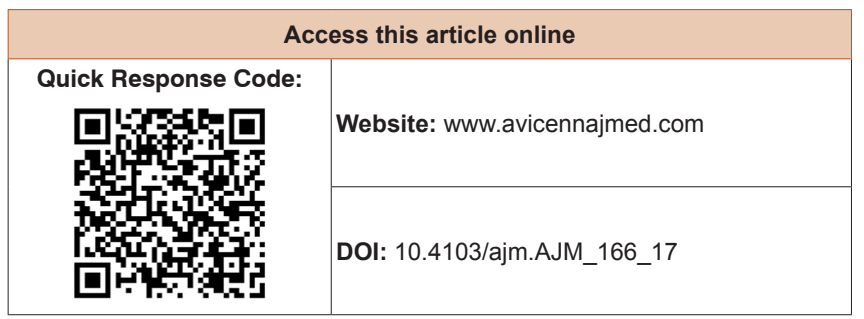

Cite this article as: Moustafa K. Promoting an academic culture in the Arab world. Avicenna J Med 2018;8:120-3.

(c) 2018 Avicenna Journal of Medicine | Published by Wolters Kluwer - Medknow 